\title{
Chemically induced skin carcinogenesis: Updates in experimental models (Review)
}

\author{
MONICA NEAGU ${ }^{1,2}$, CONSTANTIN CARUNTU $^{3,4}$, CAROLINA CONSTANTIN $^{1}$, DANIEL BODA ${ }^{4}$, \\ SABINA ZURAC ${ }^{5}$, DEMETRIOS A. SPANDIDOS ${ }^{6}$ and ARISTIDIS M. TSATSAKIS ${ }^{7}$
}

\author{
${ }^{1}$ 'Victor Babes' National Institute of Pathology, Bucharest 050096; ${ }^{2}$ Faculty of Biology, University of Bucharest, Bucharest 76201; \\ ${ }^{3}$ Department of Physiology, 'Carol Davila' University of Medicine and Pharmacy, Bucharest 050474; ${ }^{4}$ Department of Dermatology, \\ 'Prof. N. Paulescu' National Institute of Diabetes, Nutrition and Metabolic Diseases, Bucharest 79811; ${ }^{5}$ Department of Pathology, \\ 'Colentina' Clinical Hospital, Bucharest 72202, Romania; ${ }^{6}$ Laboratory of Clinical Virology, Medical School, \\ University of Crete, Heraklion 71409; ${ }^{7}$ Department of Forensic Sciences and Toxicology, \\ Medical School, University of Crete, Heraklion 71003, Greece
}

Received January 27, 2016; Accepted March 16, 2016

DOI: $10.3892 /$ or.2016.4683

\begin{abstract}
Skin cancer is one of the most common malignancies affecting humans worldwide, and its incidence is rapidly increasing. The study of skin carcinogenesis is of major interest for both scientific research and clinical practice and the use of in vivo systems may facilitate the investigation of early alterations in the skin and of the mechanisms involved, and may also lead to the development of novel therapeutic strategies for skin cancer. This review outlines several aspects regarding the skin toxicity testing domain in mouse models of chemically induced skin carcinogenesis. There are important strain differences in view of the histological type, development and clinical evolution of the skin tumor, differences reported decades ago and confirmed by our hands-on experience. Using mouse models in preclinical testing is important due to the fact that, at the molecular level, common mechanisms with human cutaneous tumorigenesis are depicted. These animal models resemble human skin cancer development, in that genetic changes caused by carcinogens and pro-inflammatory cytokines, and simultaneous inflammation sustained by pro-inflammatory cytokines and chemokines favor tumor progression. Drugs and environmental conditions can be tested using these animal models. keeping in mind the differences between human and rodent skin physiology.
\end{abstract}

Correspondence to: $\mathrm{Dr}$ Constantin Caruntu, Department of Physiology, 'Carol Davila' University of Medicine and Pharmacy, 8 Bulevardul Eroii Sanitari, Bucharest 050474, Romania

E-mail: costin.caruntu@gmail.com

Key words: skin cancer, chemically induced carcinogenesis, mouse model

\section{Contents}

1. Introduction

2. Human skin versus animal model skin: Similarities and peculiarities in carcinogenesis

3. Inflammation triggering carcinogenesis

4. History of experimental skin carcinogenesis

5. Refining the model of carcinogenesis

6. Advancing knowledge using models of skin carcinogenesis

7. Testing avenues using animal models of skin carcinogenesis

8. Conclusion and perspectives

\section{Introduction}

During evolution, the skin has been constantly exposed to complex agents, such as physical (sun rays) and biological assaults (microbes and or allergens); in response to these assaults, the skin has developed specific networks of molecular and cellular sensors to counteract all these aggressors (1). The skin is the largest organ with immune function, and represents an intrinsic network of non-immune and immune cell and molecules that interrelate $(2,3)$. Throughout ontogeny, apart from being exposed to biological aggressors, skin is also exposed to potentially harmful environmental compounds (cigarette smoke, automobile emissions, industrial soot and groundwater) (4).

Due to these many and complex aggressions, skin cancer appears in many forms and it is one of the most common malignancies affecting humans. Owing to various factors, the incidence of skin cancer has increased over the years $(5,6)$. Skin cancer is a multifactorial disease in that it has a strong genetic component. In addition, several environmental factors also play a role in this increased incidence. Among the environmental factors, the most significant is the exposure to ultraviolet (UV) radiation (7), doubled by the exposure to certain chemicals, medication use or stress. All these connected factors may modulate many skin physiopathological processes (8-11), and trigger the initiation and progression of skin cancer (5). 
Skin carcinogenesis is a complex, multistep process $(12,13)$, and the study of early alterations in the skin and of the mechanisms involved, as well as the development of novel therapeutic strategies are of interest for both scientific research and clinical practice. Moreover, the striking increase in both the number of new topical chemical entities and their biological effects creates the need to understand the intimate molecular mechanisms that underlie their in vivo effects. Developing in vivo systems for the rapid evaluation of potential drugs is always the concern of researchers. Mouse models of skin carcinogenesis remain one of the most commonly available and cost-effective animal models. In this type of model, agents, either applied topically or systemically, can be studied at the earliest possible stage in the development of drugs/new therapies. In contradiction to the undemanding condition of this model, there is a complex array of mouse strains with distinctive biological behavior to this standard protocol, and this review intends to highlight this distinction and to flag the reported particularities.

\section{Human skin versus animal model skin: Similarities and peculiarities in carcinogenesis}

Immunologically, mice are the first option when studying immunotoxicology. From this point of view, $>15$ years ago, the sequencing of human and mice genomes revealed that approximatley 300 genes are unique to mice in comparison to humans (14).

A comprehensive review, published $>10$ years ago, demonstrated that although there are differences in the skin of mice versus human skin, mice are reliable in vivo models that can be used to furnish relevant toxicological information (15). Human therapies are becoming more complex, targeting various cells/proteins/genes; hence, the information gathered from animal models should be carefully weighted in terms of extrapolating data from mice to humans. This is the reason that we have witnessed so many examples of therapies that have had perfect outcomes in experimental animal models, but have then failed to be as effective in humans (16-21).

The main immunological differences regarding the skin is that in mouse skin and mucosa, the predominant $\mathrm{T}$ cells are $\gamma / \delta \mathrm{T}$ cell receptors (TCRs), whereas in humans, $\alpha / \beta$ TCRs prevail (22).

$\mathrm{T}$ cells that are specific for mouse skin have their TCRs encoded by a single $\mathrm{V} \gamma$ and $\mathrm{V} \delta$ gene. These cells seem oligoclonal ( $\mathrm{V} \gamma 5-\mathrm{V} \delta 1$ genes are encoding for this specific TCR), are found in the epidermis, and they mainly appear as dendritic epidermal $\mathrm{T}$ cells. In human skin, $\mathrm{T}$ cells with $\alpha / \beta$ TCRs predominate in human skin, mainly in the dermis. Up to now, TCR $\gamma / \delta$ T cells were not identified in normal human skin (22) and were reported only in lymphoma cases (23). Even in mice, TCR $\gamma / \delta$ phenotype T cells can have different densities between different skin sites and different strains (24). In mice, TCR $\gamma / \delta$ T cells play important roles in tissue homeostasis and during tissue repair. These cells secrete growth factors (e.g., for keratinocytes and insulin-like growth factors), through which the crosstalk between $\gamma / \delta$ T cells from the skin and keratinocytes takes place, actively contributing to the physiology of normal skin and further contributing to wound healing (25). In humans, $\alpha / \beta$ TCR T cells are activated by CD1 antigen-presenting molecules. It has been demonstrated that a large number of T cells with CDla-autoreactive phenotype are homed to the skin, producing interleukin (IL)-22 in response to CD1a expressed on a different skin cell population, namely Langerhans cells (LCs) (26). Thus, while in mouse skin $\mathrm{T}$ cells collaborate mainly with keratinocytes, in human skin, $\mathrm{T}$ cells associate in functionality with specific dendritic cells, such as LCs.

\section{Inflammation triggering carcinogenesis}

Inflammation involves the secretion of a number of mediators from immune and non-immune cells and occurs for the purpose of the restoration of damaged tissue. Inflammation was known from the beginning of the last century (27), and is a multi-stage process, beginning with the injury inflicted upon a tissue and ending with the reconstruction of the damaged tissue.

Environmental factors can inflict this injury, whether a macro-physical trauma or a micro-trauma (e.g., overuse, friction and sunburn). At the cellular level, the disruption of the cellular membrane releases the intracellular contents into extracellular spaces. Metabolically, hypoxic changes occur, and the cells become deprived of oxygen (secondary hypoxic injury), the sodium pump fails, and cellular membrane disruption continues in adjacent cells, thus enhancing the destruction at a cellular level. This disruption generates mediators (e.g., histamine and bradykinin) that represent the first signals triggering an inflammatory response. The inflammatory response triggers hemodynamic changes: arteries dilate enhancing blood flow, inactive capillaries and venules open, the total blood flow increases, the rate of flow decreases and leukocytes bening to adhere to the vessel wall. Due to critical permeability alterations, leukocytes transmigrate to the injured site. Following the increase in chemoattractant gradient concentration, leukocytes migrate to the injured site. Neutrophils are the first cells that arrive, being the temporary first line of defense [short-lived cells (approximately $7 \mathrm{~h}$ )]; neutrophils are followed by macrophages that build up the second line of defense and can survive for months. These two type of cells process, through phagocytosis, debris/microbes, enhancing the clearance process through lymph vessels (28).

In the framework of this review, we focus on a key issue in the process of inflammation, the acute versus the chronic stages of this process (Fig. 1) that can trigger skin carcinogenesis. There is a scientific consensus to incriminate chronic inflammation as linked to carcinogenesis (29) and in mouse experimental models, this chronic inflammation is experimentally sustained in order to favor tumorigenesis.

The differences between these two stages of inflammation reside on different immunological mechanisms. During the acute inflammatory stage, innate cells secrete mediators that attract Th1-type T lymphocytes. Th1 cells secrete cytokines with antitumor activity [e.g., IL-2 and interferon (IFN)- $\gamma$ ]. Apart from T cells, factors secreted by B cells (e.g., antitumor immunoglobulins) activate cytotoxic T lymphocytes (CTLs). Hence, a cellular armamentarium is built up to protect against tumor development.

During the chronic stages of inflammation, when there is a constant activation of the immune response without actually resolving the damage inflicted to tissue, there is an accumulation of regulatory T cells, Th2 cells and activated B cells. In chronic inflammation, immune cells secrete pro-tumorigenic 
A

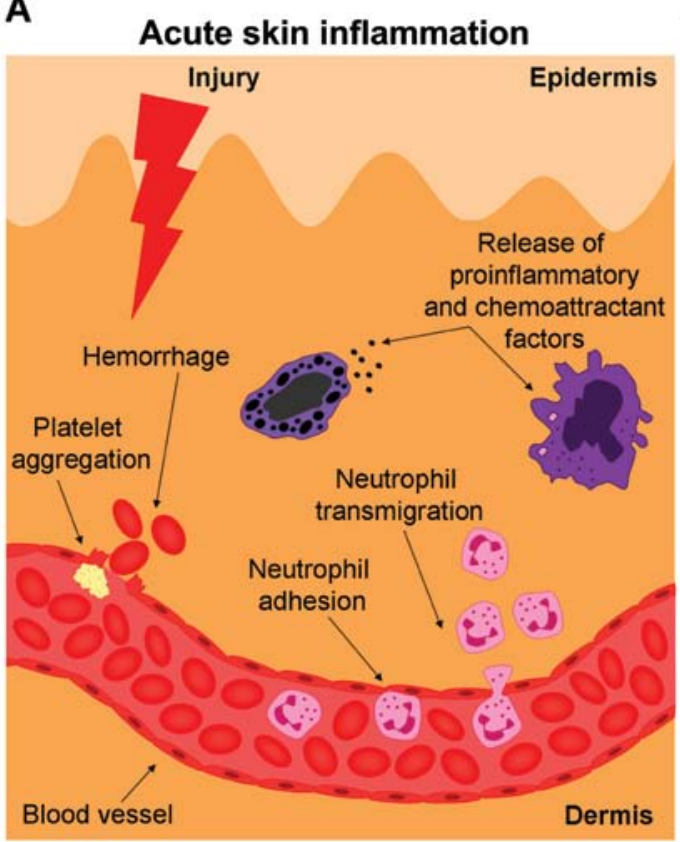

B

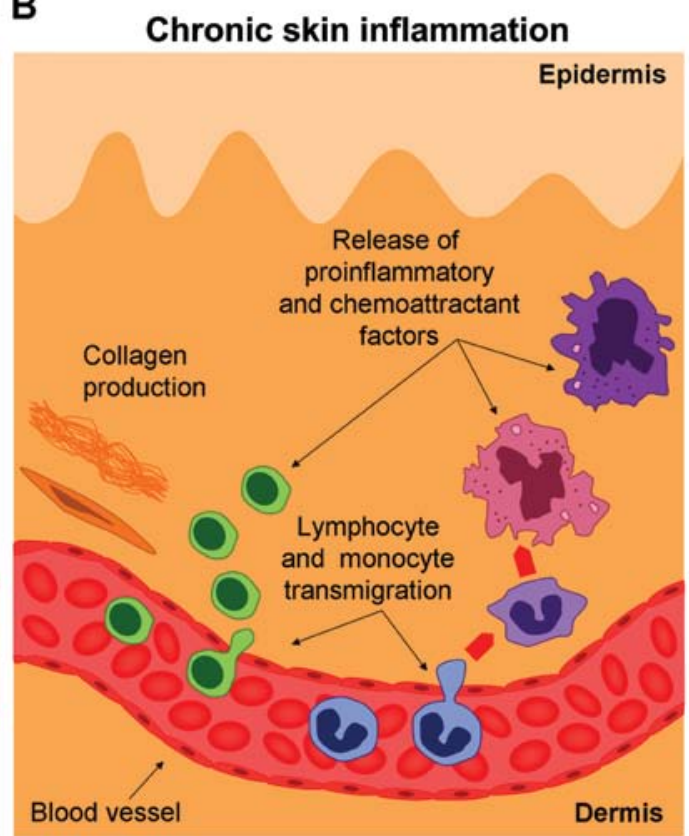

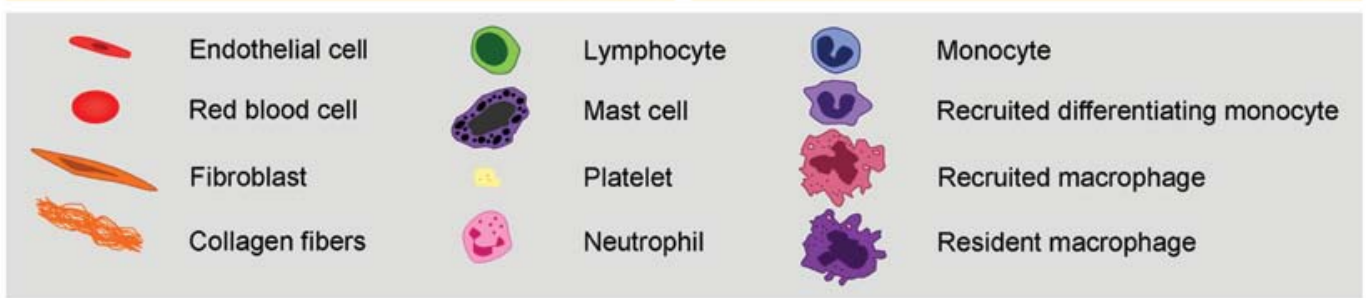

Figure 1. The cascade of acute and chronic skin inflammation. (A) The initial skin injury triggers intravascular processes that promote neutrophil adhesion and transmigration. Resident macrophages and mastocytes release pro-inflammatory factors and chemoattractants; (B) lymphocytes and monocytes have enhanced adhesion capacities and further transmigrate into the extravascular space. Transmigrated cells and resident macrophages secrete pro-inflammatory factors and chemoattractants, stimulating collagen production and perpetuating the inflammatory response (copyright from ref. 29).

factors [e.g., IL-4, -6, -10 and -13 , and transforming growth factor $\beta$ (TGF- $\beta)$ that inactivate CTL cytotoxicity, thus favoring tumor development (30).

The soluble mediators and cellular effectors of inflammation are common to the tumor microenvironment and can reside in the tumor site. Inflammatory conditions can preclude a malignant transformation and/or an oncogenic alteration sustains the inflammatory microenvironment favorable for tumor development (31), a phenomenon that is exploited in chemically induced skin carcinogenesis.

Chronic inflammation and tumorigenesis. In skin there is an established link between tissue damage, inflammation and cancer development. Tumorigenesis is based on constitutive pathway activation, while inflammation is a self-limiting process in normal conditions (32). In the framework of this review, chronic inflammation of the skin can be one of the traits for tumor initiation and progression. In animal models, chronic inflammation may be used to trigger tumorigenesis. The long-term production and the consequent accumulation of inflammatory factors (cytokines/chemokines) can induce locally an immunosuppressive milieu associated with tumor development and progression (29).

Cytokines, long-time players in inflammation, are produced in the skin by an enhanced group of resident cells [keratino- cytes, LCs, melanocytes, mast cells (MCs) and macrophages], as well as by recruited inflammatory cells (e.g., neutrophils, eosinophils and lymphocytes) (2). Generally, cytokines are synthesized following cell activation and act locally within the tissue, having a paracrine function in neighboring cells that express specific receptors or have an autocrine action in the cells producing them in an auto-regulatory loop. When the inflammatory stimulus is prolonged, cytokine production becomes excessive, and finally, this has a deleterious effect both on site and on distal sites from the original inflammation site, similar to the effects of hormones. Cytokine receptors have a mainly homologous structure; thus, various cytokines can have pleiotropic effects, acting on several targets. Beyond that, cytokines can have a synergistic effect on the same cells, while acting antagonistically on other cell types (33).

As it has already been acknowledged, in each tissue, as with the skin, a complex cytokine network is developed and this network is precisely regulated $(33,34)$; any deregulation of this cascade can trigger a tumorigenic process (Fig. 2).

Cell migration is critical for several normal processes, such as embryogenesis, the immune response, inflammation; however, it is also one of the key events in cancer cell metastasis (35). All the molecular perturbations underlying chronic inflammation as triggers for skin tumorigenesis are again the center of cell migration research. Ehm2 (a novel cancer promoter) belongs 
A

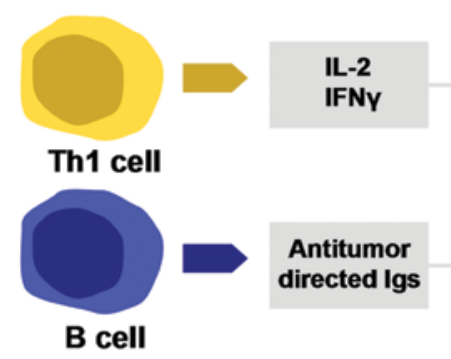

$\uparrow$ M1 macrophage phenotype $\uparrow$ Innate cytotoxic response $\uparrow$ CTL-mediated destruction $\uparrow$ APC activation $\uparrow$ NK cell
B

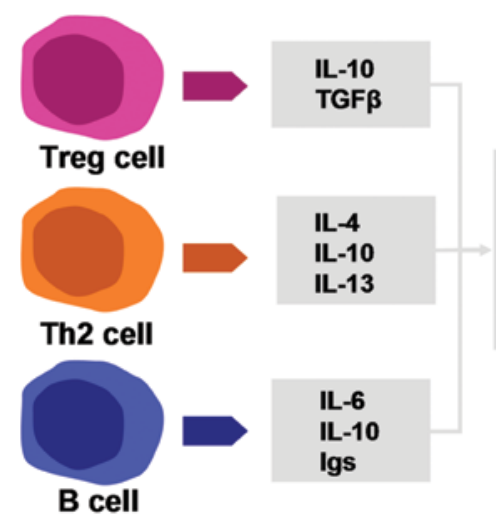

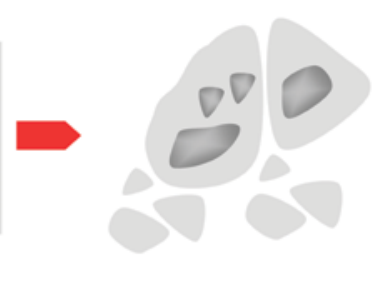

Tumor rejection $\uparrow$ M2 macrophage phenotype

$\uparrow$ Myeloid supressor cells

$\downarrow$ CTL-mediated destruction

$\downarrow$ APC activation

$\downarrow$ NK cell

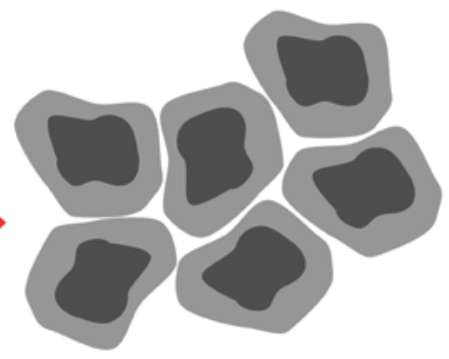

Tumor promotion

Figure 2. Elements of acute and chronic inflammation that are linked to tumorigenesis. (A) T and B lymphocytes secrete factors that induce the M1 macrophage phenotype, promote the innate immune response, promote cytotoxic T lymphocyte (CTL)-mediated destruction, enhance the antigen-presenting capacity and increase natural killer (NK) cell activity. All these processes have a potent antitumorigenic effect; (B) T and B lymphocytes secrete factors that induce the M2 macrophage phenotype, enhance myeloid suppressor activity, reduce CTL activity, decrease the antigen-presenting capacity and increase NK cell activity. All these processes have a potent pro-tumorigenic effect (copyright from ref. 29 ). IL, interleukin; IFN- $\gamma$, interferon- $\gamma$; TGF- $\beta$, ransforming growth factor $\beta$; Ig, immunoglobulin.

to the FERM family of proteins (4.1 protein, ezrin, radixin, moesin), that are involved in membrane-cytoskeletal interactions, and are linked to the metastatic event in several types of cancer, including skin cancer. In a study published in 2013, the effect of Ehm 2 knockdown on cell migration, adhesion, growth, cell cycle progression and apoptosis were reported. The authors demonstrated that Ehm2 was expressed at 3-fold higher levels in tissues with acute inflammation, compared to the chronic state. Following the knockdown of Ehm2, the expressoin of another protein was found to be decreased, namely that of neural Wiskott-Aldrich syndrome protein (Nwasp) (36). Nwasp is significant in the invasion processes as the binding of cortactin to Arp2/3 and Nwasp are key elements for invadopodia formation in melanoma cells (37). These reported results propose that Ehm2 proteins are interesting connection molecules between inflammation and the skin cancer metastatic process. In melanoma, following the knockdown of Ehm2 protein, the expression of Nwasp was downregulated, directly affecting cell migration (36).

There are intracellular pathways that are deregulated in tumorigenesis and in a non-healing wound. Thus, both processes involve common molecular and signaling pathways, such as Ras, Hedgehog and WNT (38).

Epithelial-mesenchymal transition (EMT) is a process through which epithelial cells lose some of their characteristics (cell polarity and cell-cell adhesion) and gain migratory and invasive properties, becoming mesenchymal stem cells (39). When a wound is healing, the EMT process is activated (40). Epidermal keratinocytes acquire migratory phenotypes (41) and then return to normal upon wound closure during the rebuilding of the basement membrane. In tumors, epithelial cells can harbor oncogenic mutations, undergoing EMT, a process associated with the acquisition of cancer stem cell properties (42). Another recently discovered cellular process, transdifferentiation, is a mechanism that governs the transformation of a mature somatic cell in another mature somatic cell lacking the intermediate pluripotent state or progenitor cell type phases (43). In adult tissues, transdifferentiation is not as accelerated as in more immature ones; however, in wounding, mesenchymal stem cells undergo transdifferentiation into epidermal cells, endothelial cells and pericytes $(44,45)$.

Another mechanism that can link inflammation with tumorigenesis is the fact that during wound healing, fibroblasts deposit excess collagen (during fibrosis), which leads to scar formation. This connective tissue is a microenvironment that is tumor permissive (46). As stated above, in this microenvironment, the presence/production of growth factors, cytokines and chemokines is similar in chronic wounds as in tumors, with a slight difference being in the expression levels in terms of kinetics (31) (see also Fig. 2). 
In conclusion, we can ascertain that a close association exists between chronic tissue damage, inflammation and cancer (32); in this context tumors may develop, although uncommonly, also at the site of chronic skin wounds (47).

\section{History of experimental skin carcinogenesis}

Where the story begins. One of the first recorded studies regarding two-step chemically induced carcinogenesis is that of Frei and Stephens published $>45$ years ago (48). It was actually the first study to demonstrate that tumors induced in mouse ears correlate with the induction of hyperplasia as an inflammatory response. Leucocytes migrating to the site were found to correlate with the rate of induction of hyperplasia; however, at the same time, no clear association between inflammation, hyperplasia and tumorigenesis was observed.

From these decisive results, chemically induced mouse skin carcinogenesis was the main animal model of cutaneous tumorigenesis (49-51). This model was used for evaluating antitumor drugs, but also for understanding the nature of epithelial cancers as a multi-stage process (52).

Several protocols have been developed for 'two-stage' carcinogenesis in which tumor incidence, tumoral latency, multi-staging and the progression of the skin cancer are studied. In the model of two-stage skin carcinogenesis, the tumor is initiated after a single sub-carcinogenic dose of 7,12-dimethylbenz[a]-anthracene (DMBA). This irreversible event leads to visible tumors only after the repeated application of a promoter agent, such as the phorbol ester, 12- $O$-tetra decanoylphorbol-13-acetate (TPA). Therefore, unlike one-step carcinogenesis, in two-stage carcinogenesis, the initiation and promotion phases can be noticeably separated, both functionally and temporally (52). This distinction of phases offers a tremendous advantage when studying the effects of environmental factors and/or drugs in the different stages of tumorigenesis.

Another advantage offered by this two-stage model is that tumor development can be visually monitored during the lifespan of a mouse. With this dynamic monitoring, non-invasive evaluation methods can be used (see below for images of in vivo confocal microscopy). Moreover, at the end of the experimental period, the transformed tissue can be harvested and thoroughly examined. This animal model yields good reproducible results; thus, when assessing cytostatics, chemopreventive and/or dietary agents for skin tumorigenesis, reliable results are obtained (53).

Over the past years, genes and cell signaling pathways, the molecular mechanisms that underlie tumorigenesis, were studied using this animal model $(54,55)$.

Considering the broad utilization of this animal model, its flexibility to extensive experimental approaches, as well as its unproblematic development for any animal husbandry, two-stage skin carcinogenesis developed in mice can be used for the model of human carcinogenesis when cancers of epithelial origin are studied (56).

Strain differences. One of the first studies acknowledging different strain susceptibility was published $>30$ years ago (57). In this early study, authors used two-stage skin carcinogenesis with a polycyclic aromatic hydrocarbon (DMBA) as the initiating carcinogen, and subsequently, as the promoter of carcinogenesis, croton oil. The study used LACA and BALB/c mice, namely one susceptible and one resistant strain. In this early study, the authors reported that DMBA was more effective in the LACA strain compared to the BALB/c one. Moreover, this was one of the first studies demonstrating the metabolic activation of DMBA and its transformation in the active carcinogen, a process common to both mouse strains, whether resistant or sensitive. This early study flagged strain differences in terms of the DMBA response, although DMBA was the actual promoter of carcinogenesis in both studied strains. At that time, mechanisms such as DNA repair were still under investigation and thus, strain differences as regards the induction of carcinogenesis could be only suggested to involve these mechanisms. Dissimilar to carcinogens, such as DMBA, phorbol ester promoters (component of the utilized croton oil) appear to shunt any metabolic activation, while being degraded and inactivated by epidermal cells. These early experiments with different promoters did not provide any evidence that the distinct biological behavior of different mouse strains is sustained by different promoter degradation (57).

After another 10 years, the era of transgenic mice began and the subject of strain specificity in terms of developing chemically induced carcinogenesis gained another dimension. The role of specific genes as determinants for particular behavior was acknowledged. Strain differences in terms of susceptibility to specific toxic agents are in fact an in vivo tool to be exploited and, in this light, transgenic animals that comprise specific genes can be manipulated. At that time, several experimental pathways were highlighted, pathways that now are at the post-graduate research level. It was then stated that transgenic animals can be used in several ways: to introduce a human gene encoding a drug metabolizing enzyme, or to delete and/ or modulate the expression patterns of specific within target cells (58).

In these early experiments, it was shown that the promoter of a stress-regulated gene linked to a reporter gene (lacZ or green fluorescent protein) can be inserted into the mouse genome; then upon experimental tumorigenesis, sensitive cells can be identified as the cells are carrying the reporter gene. Transgenic mice can be used for the high-throughput screening of compounds, an invaluable experimental model that can offer results regarding the tissue and cellular specificity of certain drugs (58). As early as the 1990s, authors highlighted that transgenic animal studies are complex, and that altering one gene does not mean one straightforward protein alteration. The introduction of a specific human cytochrome P450 gene can have no metabolic effect due to the overall background activity in the rodent. Drug uptake, metabolism, detoxification and repair, as parts of the complex process of toxicity, differ in primates and rodents; for example, a toxic response in one species can be totally irrelevant in another (58); however, transgenic animals in the toxicological domain have gained momentum and are speeding up the drug discovery processes.

Almost at the same time period, another team investigated the association between single gene mutations and carcinogenesis, the histological type triggered by this gene mutation and whether a novel papillomavirus (at that time) had a co-carcinogenic function (59). A two-step protocol (DMBA followed by TPA) was used to induce papillomas in several 
inbred, hybrid, and various genetically altered mice. Studying the histological types of tumors, the authors reported an increased panel of histology beginning with early follicular papillomas, along with mixed papillomas, or exophytic papillomas, hyperplastic papillomas, fibropapillomas, squamous cell carcinomas (SCCs), and MC tumors. Moreover, in these mouse models, high-, intermediate-, and non-responding groups can be obtained. The authors demonstrated that tumor induction was conditioned by skin-specific mutant genes. Papillomavirus antigens or viral genomic DNA was not present in the induced tumors. Genetic differences were first flagged in the late 1990s as underlying the strain differences (59).

Laboratory animals subjected to specific genetic manipulations can be used to not only study compounds used to induce carcinogenesis, but also to study the effects of topical chemical toxins. This was an important conclusion of the late 1990s, paving the way for the future genomic era of skin toxicology and dermato-oncology.

\section{Refining the model of carcinogenesis}

As discussed in the previous section, several decades of studies have investigated the induction of carcinogenesis in animal models. The topical administration of compounds which induce skin carcinogenesis in mice provides an easy model for studying local, systemic and environmental factors influencing tumor susceptibility, growth and progression. This model of chemically induced carcinogenesis almost as old as modern dermato-oncology and skin toxicology continues to provide a cost-effective model needed for the identification of biological, immunological and molecular pathways implicated in skin tumorigenesis. Besides these somewhat fundamental findings, this model is frequently used for topical antitumoral drug testing. For instance, the two-stage mouse carcinogenesis model was typically used for testing drugs effective for skin cancer prevention $(60,61)$. Studies regarding chemoprevention testing were reported in the SENCAR mouse, a model evaluating phenylretinamides as tumor suppressors via retinoid receptor-independent mechanism(s) (62).

In essence, this model uses the two-stage application of chemicals to the skin for the initiation and promotion of cutaneous tumors. When using a two-stage model of induction, after a single application of the initiator mutagen, DMBA, repeated applications of a pro-inflammatory phorbol ester (TPA), or phorbol 12-myristate 13-acetate (PMA) are carried out. The literature indicates that tumors that appear can be benign papillomas that regress or progress to SCC (63). Moreover, the direct appearance of SCC was reported without the presence of any pre-cancerous lesions. Thus, two-stage chemically induced carcinogenesis provides an opportunity to monitor early and late events in cancer development and progression (63).

Our experience has shown that, when we used this protocol (64), in three different mice strains, widely covering the susceptibility area in terms of chemically induced carcinogenesis (high susceptibility, nude mouse CD1-Foxn 1nu strain; medium susceptibility, CD-1 strain; and low susceptibility, C57BL/6 strain) we obtained various results. Thus, from the C57BL/6 mice, only a small percentage (5\%) developed skin lesions. Tumor formation began approximately after 25 weeks from the first DMBA application. Macroscopically,

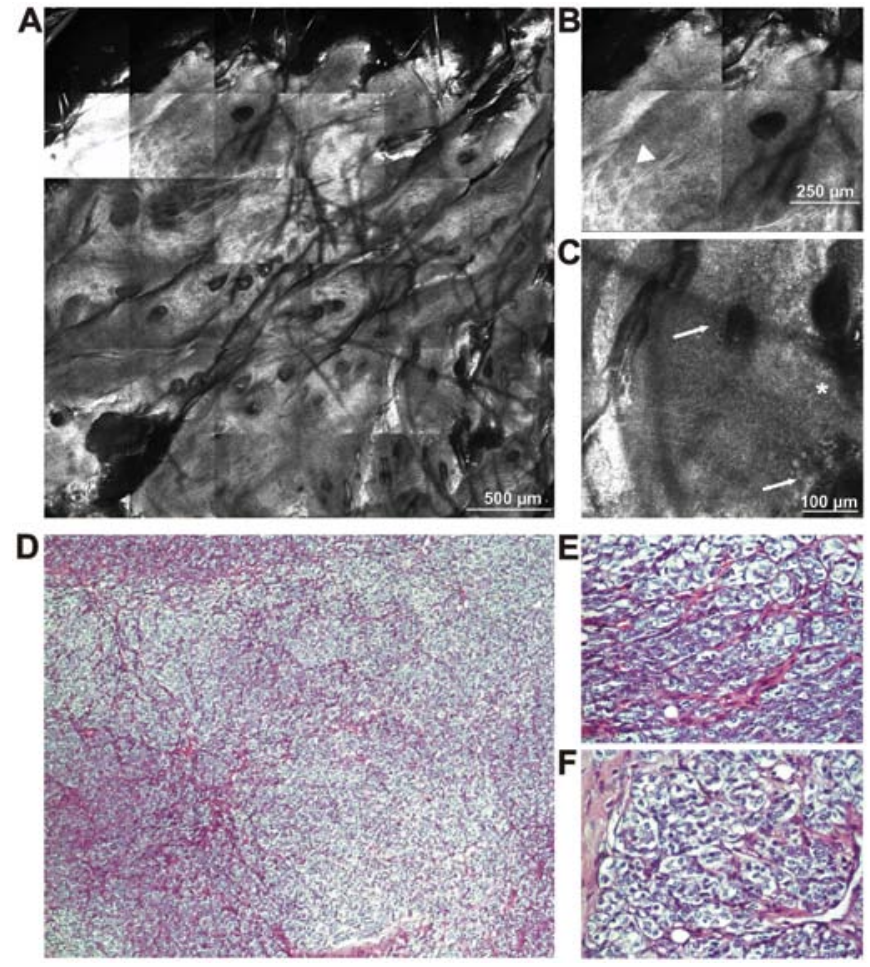

Figure 3. Reflectance confocal microscopy (RCM) and histopathological images of chemically induced skin tumors in C57BL/6 mice. (A) RCM mosaic showing a tumoral structure with an irregular architecture; (B and C) details of RCM image showing bright fiber-like structures (white arrowhead), large cells with dark nuclei (white arrows) and numerous small hyper-refractile structures (white asterisk); (D) poorly differentiated carcinoma expressing neuron-specific enolase, week cytokeratin expression, negative melanocyte markers (hematoxylin and eosin staining, original magnification, x100); (E an F) histological details (hematoxylin and eosin staining, original magnification, $\mathrm{x} 400$ ).

they displayed only one formation, round shaped, rough at palpation with a wide base. We did not observe metastases at necropsy and the histopathological identification (Fig. 3) revealed a poorly differentiated carcinoma. In order to maintain the homogeneity of the mouse model, we established a clone of tumor cells with which we established an in vivo mouse model of skin carcinoma using the C57BL/6 mouse strain.

In the CD1-Foxn 1nu mouse group, approximately $20 \%$ of the mice survived during the experiment. In the survivors, tumor formations appeared around 8 weeks from the first DMBA application and the mice were sacrificed 10 weeks after the appearance of the lesions. Macroscopically, the mice developed multi-formations, 1-3 mm in diameter, with an irregular appearance and a narrow base. No metastases were observed at necropsy and the histological examination depicted cutaneous papillomas (Fig. 4). All the presented original animal experiments were carried out in accordance with EU guidelines (65).

The mice in the CD1 group all developed skin formations. In this case, the tumor was clinically detectable as early as 5-6 weeks after the initial application. Macroscopically, there were multi formations, elongated with an irregular shape, soft at palpation, with a narrow base and a rapid growth rate. No metastases were observed at necropsy. A technology that we and others are developing in animal models is in vivo reflectance confocal microscopy (RCM). This modern imaging technique allows for the non-invasive 'quasi-histological', real-time 


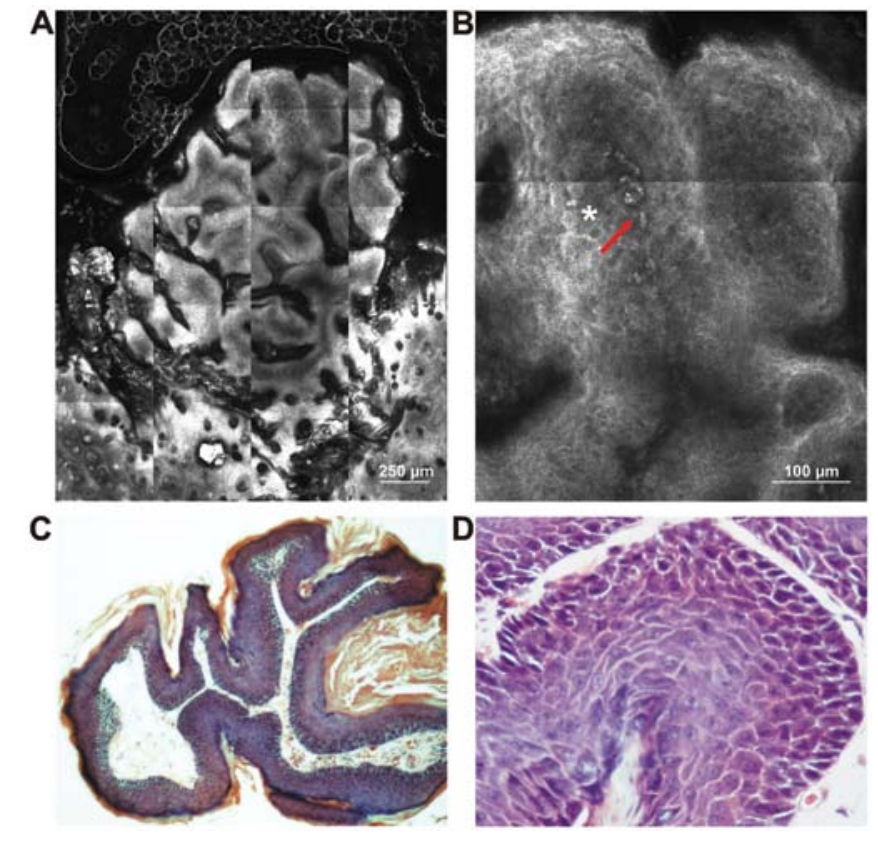

Figure 4. (A) Reflectance confocal microscopy (RCM) mosaic showing a tumoral structure with a multilobular architecture; (B) details of RCM image showing atypical cells (white asterisk) and blood vessels (red arrow); (C) cutaneous papillomas presenting intra-epithelial keratinocytes neoplasia I/II (hematoxylin and eosin staining, original magnification, x100); (D) histological detail (hematoxylin and eosin staining, original magnification, $x 400$ ).

evaluation of both human and murine skin structure (66-68,71). Using in vivo confocal microscopy for investigating skin cancer in animal models enables the observation of abnormal tissue architecture, along with the identification of atypical structures and all these observations are made during the real-time assessment of blood flow through dermal vessels. Publications regarding the use of this technology in mouse models are not abundant, but cover an area of continuous development. This technique is a new approach for monitoring tumor progression and the therapeutic effects of anticancer agents in skin cancer $(68,69,72)$.

Recently, another study demonstrated that the stages of human and mouse carcinogenesis are not super-imposed. The authors reported that tumor necrosis factor- $\alpha$ (TNF- $\alpha$ ) promotes endogenously carcinogenesis and that TNF- $\alpha$-inducing protein (Tip $\alpha$ ) favors EMT and, subsequently, the progression of cancer (73). In this light, the overall inflammatory process should be reconsidered in this chemically induced skin carcinogenesis, linking the promoter chemicals to inflammatory proteins. Bridging the early studies of 'inflammation', as carcinogenesis points toward the role of TNF- $\alpha$ in tumor-promoting inflammation, this updated study involves another factor in chemically induced carcinogenesis, namely immunological players (73). Our experience suggests that several inflammatory cytokines tested in serum match the evolution of skin tumors in mouse models (74).

Thoroughly recently reviewed (75), this sequential administrated tandem, DMBA-TPA, leads to the appearance of a large number of benign papillomas, more or less developing into SCC. At the molecular level, tumorigenesis is initiated with the mutational activation of the Ha-Ras oncoprotein. In human SCC, HA-RAS mutations are rarely reported, while frequent HA-RAS-mutated tumors are reported in melanoma following treatment with B-raf inhibitors. This recent finding indicates the probable existence of HA-RAS-mutated cancer stem cells in the actual tumors. In a similar manner, UV-induced human SCC displays mutations in TP53, a tumor suppressor gene. This published review emphasizes the differences in skin tumorigenesis which is chemically induced, but concomitantly shows that these characteristics are common to humans as well. In making a comparison of the differences in the skin tumor microenvironment between the mouse model and humans, common molecular mechanisms were depicted and the authors recommend the use of mouse models in skin toxicological testing (75). In $\mathrm{C} 3 \mathrm{H} / \mathrm{HeN}$ mice, the exposure of the skin to $\mathrm{UV}$ radiation induced the activation of $\beta$-catenin in a time- and dose-dependent manner. Mice deficient in cyclooxygenase-2 (COX-2) subjected to UV radiation exhibited a lesser activation of $\beta$-catenin. In SKH-1 hairless mice exposed to UV radiation, the activatoin of $\beta$-catenin signaling was also observed as well as the development of UV radiation-induced skin tumors. All the accumulated data from the study of photocarcinogenesis led to the conclusion that the activation of the $\beta$-catenin pathway can induce skin carcinogenesis (76).

\section{Advancing knowledge using models of skin carcinogenesis}

Genomics. The majority of publications in the genomics investigating field have focused on studying the environmental factors, such as UV radiation and carcinogens as potent inductors of epigenetic alterations.

Exposure to environmental mutagens or simply spontaneous errors can induce somatic mutations, leading to the development and/or progression of cancer. The epigenome can also undergo chemically induced or spontaneous alterations, leading towards carcinogenesis. Next-generation sequencing can identify genetic variants, somatic mutations, gene expression profiles, and epigenetic alterations with single-base resolution. All this new technology was put in use to provide insight into tumorigenesis driven by environmental factors (77).

Moreover, nutritional and dietary resources can modify individual susceptibility through changes in the epigenome. Epigenetics hence aims to identify the health risks of environmental toxicants combined with dietary and nutritional ones. The epigenetic end-points reported by authors highlight global hypomethylation and specific hypermethylation at diverse tumor suppressor genes upon environmental exposure. Furthermore, a series of conditions were flagged that could influence the epigenetic effects of environmental factors: namely the dynamics of exposure, dose, gender, organ-target and age were examined for alterations in the epigenome. The effects of environmental factors can be balanced by nutritional/dietary agents, reversing their epimutagenic effects (77).

In a study published in 2014, the genome-wide DNA methylation profile was investigated in a model of UVB- and DMBA/TPA-induced skin cancer (78). In that study, the SKH-1 strain was subjected to UV radiation and in CD-1 mice, carcinogenesis was induced by DMBA/TPA. The authors reported $>6,000$ genes in the UVB group and $>5,400$ genes in the DMBA/TPA group that proved an enhanced CpG methylation. Using ingenuity pathway analysis, the first pathways in which these deregulated methylation appeared were the ones 
related to tumorigenesis. Hence, of the deregulated pathways, cAMP-mediated signaling, G protein-coupled receptor signaling and PTEN signaling were associated with UV radiation, while protein kinase A (PKA) signaling and xenobiotic metabolism signaling were associated with DMBA/TPA carcinogenesis. As stated in the inflammation-carcinogenesis section, the inflammatory processes can sustain tumorigenesis (78).

Thus, in that study, IL-6-related inflammatory pathways had alterations in the methylation profiles when skin was subjected to UVB irradiation. Altered genes were classified in the UVB and DMBA/TPA models, while establishing in silico their molecular interaction networks. The authors demonstrated that methylation profiles of skin subjected to environmental factors (UVB irradiation or chemical carcinogenesis DMBA/TPA) can shed light on epigenetic gene regulation in skin carcinogenesis (78).

Actually the first study on the aberrant methylation of $\mathrm{Nr} 4 \mathrm{a} 3$ exon $3 \mathrm{CpG}$ island was reported in a multistep mouse model of skin carcinogenesis (79).

Studies published in 2014 demonstrated that many cancer susceptibility loci are located throughout the genome $(80,81)$. Mapping these loci in a mouse model of skin cancer, the authors demonstrated strong genetic loci that render resistance to chemically induced skin papillomas. These loci are located on chromosomes 4 and 7. Combining congenic mapping (congenic mouse strain, FVB.MSM-Stmm3) and allele-specific alteration analysis of these loci located on chromosome 4, it was demonstrated that Stmm3 (skin tumor modifier of MSM 3) responsible genes influence the formation of papillomas in two-stage skin carcinogenesis by regulating papilloma growth rather than development (80). The same group, in the same year, demonstrated that Stmm1 may be responsible for papillomagenesis in two-stage skin carcinogenesis by regulating epidermal quiescent stem cells (81).

Genetically modified animals have been used as valuable tools in depicting the carcinogenic process. A number of studies have used these animals in the animal model of two-stage skin carcinogenesis in order to depict the roles of certain genes involved in epithelial carcinogenesis $(54,82,83)$. In these animals, the functionality of genes can be studied throughout the evolvement of the carcinogenesis process. Targeting genetic modifications that can modify cutaneous tissue has allowed different genetic manipulations (gene overexpression or gene deletion) in particular skin compartments, recapitulating spontaneous genetic events in tumorigenesis (84).

In the search for new therapuetic targets from the panel of signaling pathway molecules, transgenic mouse have been used. The study by Wilker et al demonstrated that using LY294002 (a PI3K inhibitor), in a transgenic mouse model that overexpressed human insulin-like growth factor-1 (IGF-1), emphasized the role of PI3 kinase and Akt-mediated signaling in epithelial carcinogenesis (85).

MicroRNAs (miRNAs or miRs) as regulators of gene expression came into the spotlight in the last 10 years $(86,87)$. Therefore, it was observed that the exposure to different carcinogens also alters miRNA expression (88-90). miRNA expression differs in the different stages of chemically induced carcinogenesis. Carcinogenic agents are potent miRNA expression deregulators, while non-carcinogenic chemicals have a lesser influence on miRNAs. Their expression also differs in different biological systems. Hence, there are increased changes in cancer-target tissues in comparison to the non-target tissues following an acute or a chronic exposure to carcinogens. The families of deregulated miRNAs in carcinogens regulate genes involved in xenobiotic metabolism, carcinogen-induced hypomethylation, DNA repair, apoptosis, cell proliferation, tumor suppression, cell transformation, oncogenesis, tumor angiogenesis, tumor progress and malignant transformation (91). Moreover, there are miRNAs with double functions, such as putative oncogenes or tumor suppressor genes (92). Carcinogens can influence the balance between these functions and drive their functions toward tumorigenesis. As recently demonstrated, miRNAs specific to carcinogen exposure can be used as biomarkers for genotoxicity and carcinogenicity (93).

The clear message conveyed from these data is that new endpoints of environmental toxicants should be found and that more attention should be paid to finding measure to prevent environment-related diseases.

Proteomics. As the domain of proteomics is rapidly evolving, mouse models of chemically induced carcinogenesis have also taken advantage of this area. The differences in the susceptibility between strains reside in the genetic diversity that triggers protein differences. In a recent study, specific protein or signaling pathway alterations were investigated in association to this susceptibility (94). Examining the epidermis proteome in DBA/2 sensitive and C57BL/6-resistant mice upon the administration of TPA, 19 differentially expressed proteins were found. Five proteins were calcium-binding proteins: annexin A1, parvalbumin $\alpha$, S100A8, S100A9 and S100A11. The S100A8 and S100A9 protein levels were found to be increased when using a different mouse model with the topical application of tumor promoters, okadaic acid and chrysarobin. When examining the associatoin between these 19 upregulated proteins, it was shown that they are active players in several inflammatory networks involved in skin tumor promotion, such as TNF- $\alpha$ and nuclear factor (NF)- $\kappa$ B. Nucleic acid mRNAs for various proteins such as TNF, Nfkb1, IL-22, IL-1b, and chemokines such as $\mathrm{Cxcl1}, \mathrm{Cxcl} 2$ and $\mathrm{Cxcl} 5$ were found to be highly expressed following the administratio of TPA in DBA/2 mice in comparison to $\mathrm{C} 57 \mathrm{BL} / 6$ mice. These reported results indicate that inflammatory genes can sustain the basis of genetic differences in susceptibility in mouse models of chemically induced carcinogenesis (94). Apart from inflammatory processes that can account for these different effects, tetraspanins, cell-surface proteins present on almost all cell and tissue types have been shown to be involved (95). During two-stage mouse skin chemical carcinogenesis, CD151 favors tumorigenesis, inducing a more rapid development, multiplicity, size and progression to SCC in this model. In human skin developing SCC, CD151 expression is increased. CD151 is associated with the activation of the transcription factor, signal transducer and activator of transcription 3 (STAT3), and PKC $\alpha-\alpha 6 \beta 4$ integrin. CD151-PKC $\alpha$ is associated with a more invasive SCC. In mouse models at least, CD151 was proven to be a future antitumor therapy target (96). In a recent study, in a model of DMBA-induced skin carcinogenesis using PKC $\alpha$ knockout mice, it was shown that PKC $\alpha$ suppresses tumor formation, but not tumor growth and progression to skin carcinogenesis (97). Using IL-6 and TNF- $\alpha$-deficient mice in chemically induced skin carcinogenesis, it was also demon- 
strated that IL-6 is not the main pro-inflammatory cytokine that promotes tumorigenesis of the skin. The authors concluded using this model that individual cytokines have distinct and discrete roles in tumor promotion (98).

Proteomics still has an important input in the nearby future in this domain as its rapid evolving methodologies find their place in quantifying the proteome behind the subtle process of tumorigenesis $(99,100)$.

\section{Testing avenues using animal models of skin carcino- genesis}

Determining how close we are to the human scenario. The presented animal model runs through the characteristics of human multi-stage carcinogenesis. As reported several years ago, it seems that mutations within stem cell niches can be the initial step in the flow of events leading to tumorigenesis $(101,102)$. At the genetic level, mutations and genes that are activated resemble those identified in humans. Therefore, when mutations in ras family members appear, receptors of the epidermal growth factor (EGFR) are activated, signaling pathways of Stat 3 and Akt-mediated are activated and the mutations of $T G F-\beta 1$ and Tp53 occur, and these are all genetic processes that seem common in both species (49).

As humans are subjected to multiple carcinogenic doses, mainly accumulating low doses, this two-stage skin carcinogenesis protocol uses both carcinogens and promoting agents, as in an environmental scenario. Furthermore, in human cancers, there is a long latency that is also mimicked by the promotional component for tumor development (103). As a result, there is a commonly agreed opinion that this mouse model can be utilized to study the mechanistic basis of human epithelial cancers.

Drug testing using the model of skin carcinogenesis. The toxicological drug testing area is a domain that frequently uses this mouse model.

The effect of nano-sized titanium dioxide particles $\left(\mathrm{TiO}_{2}\right)$, as a growing component used in cosmetics, sunscreens and food additives, was tested in the model of two-stage skin chemical carcinogenesis using DMBA and afterwards the tested compound (104). The topical application of non-coated rutile-type $\mathrm{TiO}_{2}$ did not trigger any UV-induced skin carcinogenesis in rats, probably due to the lack of penetration of $\mathrm{TiO}_{2}$ into the epidermis. The same authors switched to chemically induced skin carcinogenesis to test the effect of silicone-coated $\mathrm{TiO}_{2}$. They used mice, human c-Ha-ras proto-oncogene transgenic mice (rasH2) and resistant $\mathrm{CD}-1$ ones. The compound did not influence the DMBA carcinogenesis in sensitive mice or resistant mice, possibly due to the lack of penetration through the epidermis (104).

In another study, the efficacy of topically applied liposome-encapsulated tamoxifen (TAM) in a model of DMBA-TPA-induced skin tumorigenesis in order to potentially decrease its systemic toxicity was tested. TAM was encapsulated in special liposomes and the incidence of papillomas was examined (105). This recent study demonstrated the inhibition of skin carcinogenesis when liposome conditioned drug was used, this finding brining good news for the future use of liposomal systems/drugs in skin cancer (105).
Agaro-oligosaccharides (AGOs) studied in in vitro models have been proven to suppress nitric oxide (NO) levels, as well as the production of prostaglandin E (PGE) and pro-inflammatory cytokines (106). Continuing this endeavour, in the two-stage mouse model of skin carcinogenesis, the administration of AGOs delayed the appearance of tumors and decreased the number of tumors. PGE2 was shown to be suppressed by AGO intake in a model of TPA-induced ear edema, while COX-2 and microsomal PGE synthase-1 were found to be downregulated. As stated above, this was a mouse model that reported results of the anti-tumor effects of AGOs, as well as of the anti-inflammatory, PGE-mediated effects (106).

As demonstrated in another study, the topical administration of the $\beta \mathrm{G}$ inhibitor, D-glucaro-1,4-lactone (1,4-GL), or D-glucuronic acid- $\gamma$-lactone (GUL) its precursor, to SENCAR mice with skin carcinogenesis, epidermal hyperplasia was significantly reduced along with a decrease in inflammation (107). Moreover, Ha-ras mutations were reduced upon experimental therapy. That study demonstrated that whether administered topically or through diet, therapy with GUL or 1,4-GL was effective in hindering experimental skin tumorigenesis (107).

Natural products testing. As there is a continuous effort to establish dietary routes of harmful compounds (108), over the past years, several papers were published showing results of natural compound testing in animal models of skin carcinogenesis and these models are particularly suited for the evaluation of the effects of dietary factors/dietary manipulations on tumor development.

Potential natural compounds can be evaluated for their effects on cutaneous tumor initiation, promotion and/or progression; several years ago, a study was published on the anti-inflammatory effects of resveratrol in this model (109). Kleiner et al also showed that the delivery of isopimpinellin from citrus, prior to exposure to DMBA, significantly inhibited tumor initiation (110). Singh et al showed that silymarin was effective at blocking tumor formation and at promoting even the regression of established tumors, this effect being dependent on the sequence of delivery (111). The topical application of rapamycin was reported as a chemopreventive agent, leading to the regression of papillomas in a model of chemically induced carcinogenesis $(55,112)$.

For testing the hydroalcoholic extract of Brazilian red propolis (HERP), an animal model of on dermal carcinogenesis was used. A single DMBA agent was used and animals treated with HERP exhibited significantly decreased tumor multiplicity throughout the 5 weeks of tumor promotion. Administered orally in a murine model of chemically induced SCC, this natural product exerted a significant modulatory effect on the formation, differentiation and progression of tumors (113).

In a previous study (114), geraniol, an acyclic monoterpene alcohol, was tested in a mouse model of DMBA-induced skin carcinogenesis without any inflammatory compound, and skin tumors occurred in all mice. The animals were orally administered geraniol and monitored for lipid peroxidation and antioxidant status. The yielded revealed positive results; geraniol at certain doses prevented tumor formation and regulated the antioxidant status. As the authors explained, the model yielded clear-cut results; geraniol inhibited tumor cell 
proliferation, modulated detoxification agents and enhanced free radical scavenging (114).

In another study, in Swiss albino mice exposed to DMBA, the chemopreventive efficacy of rosmarinic acid was reported (115). As in the above-mentioned study, phase I and II detoxification agents, lipid peroxidation by-products, antioxidants and apoptotic biomarkers were assessed. The authors reported that they succeeded in inducing SCC in all the mice within 15 weeks of topically applying only DMBA. The investigated parameters were found modified in the SCC tumor-bearing animals, while extremely positive clinical results were obtained in the animals treated orally with rosmarinic acid. The treated animals did not develop tumors, while animals already bearing SCC tumors exhibited a normalization of all the tested detoxification agents, lipid peroxidation by-products, antioxidants and apoptotic markers (p53, Bcl-2, caspase-3 and caspase-9) (115).

SHR mice subjected to DMBA protocol were also tested for the efficacy of melatonin and metformin. The published results indicated that melatonin and metformin, significantly attenuated tumorigenesis and decreased the overall lipid peroxidation levels (116).

Green tea is also a natural product that exerts benefitial effects on skin carcinogenesis in animal models. Green tea polyphenols (GTPs), mainly epigallocatechin-3-gallate (EGCG) were tested, among other types of cancer, in skin cancer models as well. It was demonstrated that GTPs/EGCG can promote anti-neoplastic processes, apoptosis, cell cycle arrest and can suppress metastasis in tumor cells, but not in normal cells. The reported difference possibly reside in the molecular mechanisms triggered by GTPs/EGCG in signaling pathways in transformed cells versus normal ones (117).

This model is also suitable for investigating the effects of dietary intake on carcinogenesis as caloric restriction is known to inhibit/delay the phase in which the tumor is promoted (118). The altered energy balance that can induce tissue-specific alterations, along with systemic effects can be evaluated in this type of animal model $(119,120)$.

Studies on the chemoprevention of skin cancer have taken advantage of the two-step mouse model of carcinogenesis. The plant flavonoid, silymarin, was proven to be effective against chemical/photo carcinogenesis. In several models of skin carcinogenesis, the topical administration of silymarin inhibited the effects of DMBA, as well as those of tumor promoters, such as TPA, mezerein, benzoyal peroxide and okadaic acid (121). The same chemopreventive effects were obtained for UVB-induced skin carcinogenesis (122). It seems that the actual effects of this flavonoid are its antioxidant, anti-inflammatory and immunomodulatory characteristics that hinder inflammation and evolution to tumorigenesis. In clinical studies, this flavonoid was reported to reduce the toxicity associated with chemotherapy (123).

Taking into account the data from recent reports, it can be emphasized that in the last couple of years, the study of the topical and systemic antitumor effects of 'green' drugs has benefited from this mouse model. As in any study on chemoprevention or dietary intervention, the efficacy of the test compound/drug studied should be carefully examined and coherent conclusions should be drawn for proper translation into human pathology.

\section{Conclusion and perspectives}

We can outline several aspects in the dermato-oncology and skin toxicology testing area that uses chemically induced skin carcinogenesis. Thus, there are both pros and cons for the utilization of this model.

There are important strain differences in histological type, development and clinical evolution of the skin tumor. These differences are enhanced by the fact that human skin tumorigenesis can comprise other pathways and we should be aware of the existing limitations. In this methodology, mice develop primarily papillomas, without any direct human equivalent. The subsequent SCC tumors that develop through tumorigenesis histologically resemble human SCC tumors. For the chemical initiation, in mice, Hras is the primary target, while in humans, Tp53 appears to bear the gene mutation in human non-melanoma skin cancer (124). The Hras gene from mouse skin closely resembles the gene found mutated in other human epithelial cancers (lung, colon and pancreatic cancers) (125). The last draw-back is that the two-stage model of skin carcinogenesis model is limited when studying metastasis, as the rate of metastatic cutaneous tumors is quite low (126).

The advantages of this model reside in the fact that upon genetic manipulation, the model can mimic the exact genetic and phenotypic changes of certain skin disease conditions. By doing so, drug target validation, preclinical testing and biomarker discovery can take advantage of rapid and oriented results. The roles of potential cancer risk modifier genes, such as proto-oncogenes, and/or tumor suppressor genes in complex processes such as initiation, promotion and progression can be additionally studied in these murine models.

Despite the stated differences, authors recommend the using of mouse models for skin toxicology testing because at the molecular level, common mechanisms are depicted. As in human cancer development, genetic alterations caused by carcinogens and pro-inflammatory cytokines, simultaneous inflammation sustained by pro-inflammatory cytokines and chemokines favor tumor progression.

One of the main issues in testing environmental factors and/or drugs is the similarities between the effects observed in vitro versus the ones registered in vivo. Moreover, another outstanding issue is to what extent we can rely on the experimental animal models when extrapolating the results to humans.

The newly released ToxCast phase II results, demonstrate that high-throughput assays for characterizing rodent toxicants, can integrate both bioactivity and chemical structure. ToxCast phase I has shown that research on drugs combined with the intensive use of omics technologies, are mandatory for combining biological and chemical information in exploring the in vitro to in vivo connection (127).

This domain still needs to explore in depth the interrelation between cells of the immune system and tumor cells, in the continuous search to unravel the intimate molecular mechanisms that trigger skin tumorigenesis $(128,129)$.

\section{Acknowledgements}

The authors would like to thank Dr Bogdan Marinescu and Dr Gheroghita Isvoranu from the 'Victor Babes' National Institute of Pathology Animal Husbandry for providing 
the tissue samples from the models of chemically induced skin-carcinogenesis. The author Constantin Caruntu was granted a Young Researchers grant no. 33891/2014 financed by 'Carol Davila' University of Medicine and Pharmacy, Bucharest. Project received funding support through UEFISCDI research project no. ID-PCE-2011-3-0918.

\section{References}

1. Bos JD: The skin as an organ of immunity. Clin Exp Immunol 107 (Suppl 1): 3-5, 1997.

2. Bos JD: Skin immune system: Cutaneous immunology and clinical immunodermatology. 3rd edition. CRC Press, Boca Raton, FL, pp3-13, 2005.

3. Neagu M: The immune system-a hidden treasure for biomarker discovery in cutaneous melanoma. In: Advances in Clinical Chemistry. Vol 58. Makowski GS (ed). Academic Press, Burlington, ON, pp89-140, 2012.

4. Elentner A, Ortner D, Clausen B, Gonzalez FJ, FernándezSalguero PM, Schmuth M and Dubrac S: Skin response to a carcinogen involves the xenobiotic receptor pregnane $\mathrm{X}$ receptor. Exp Dermatol 24: 835-840, 2015.

5. de Vries E, Trakatelli M, Kalabalikis D, Ferrandiz L, Ruiz-de-Casas A, Moreno-Ramirez D, Sotiriadis D, Ioannides D, Aquilina S, Apap C, et al; EPIDERM Group: Known and potential new risk factors for skin cancer in European populations: A multicentre case-control study. Br J Dermatol 167 (Suppl 2): 1-13, 2012.

6. Diepgen TL and Mahler V: The epidemiology of skin cancer. $\mathrm{Br}$ J Dermatol 146 (Suppl 61): 1-6, 2002.

7. Ene CD, Anghel AE, Neagu M and Nicolae I: $25-\mathrm{OH}$ Vitamin D and interleukin-8: Emerging biomarkers in cutaneous melanoma development and progression. Mediators Inflamm 2015: 904876 2015.

8. Căruntu C, Grigore C, Căruntu A, Diaconeasa A and Boda D: The role of stress in skin diseases. Intern Med 8: 73-84, 2011.

9. Căruntu C, Ghiţă MA, Căruntu A and Boda D: The role of stress in the multifactorial etiopathogenesis of acne. Ro Med J 58 : 98-101, 2011.

10. Căruntu C, Boda, D, Musat S, Căruntu A and Mandache E: Stress-induced mast cell activation in glabrous and hairy skin. Mediators Inflamm 2014: 105950, 2014.

11. Caruntu C, Boda D, Constantin C, Caruntu A and Neagu M: Catecholamines increase in vitro proliferation of murine B16F10 melanoma cells. Acta Endocrinologica (Buc) 10: 545-558, 2014.

12. Marks F and Fürstenberger G: Experimental evidence that skin carcinogenesis is a multistep phenomenon. Br J Dermatol 115 (Suppl 31): 1-8, 1986

13. Bibby MC: The specificity of early changes in the skin during carcinogenesis. Br J Dermatol 104: 485-488, 1981.

14. Waterston RH, Lindblad-Toh K, Birney E, Rogers J, Abril JF, Agarwal P, Agarwala R, Ainscough R, Alexandersson M An P, et al; Mouse Genome Sequencing Consortium: Initial sequencing and comparative analysis of the mouse genome. Nature 420: 520-562, 2002 .

15. Mestas $\mathbf{J}$ and Hughes CC: Of mice and not men: differences between mouse and human immunology. J Immunol 172 2731-2738, 2004.

16. Shepherd FA and Sridhar SS: Angiogenesis inhibitors under study for the treatment of lung cancer. Lung Cancer 41 (Suppl 1) S63-S72, 2003.

17. Oehler MK and Bicknell R: The promise of anti-angiogenic cancer therapy. Br J Cancer 82: 749-752, 2000

18. Panitch HS, Hirsch RL, Haley AS and Johnson KP: Exacerbations of multiple sclerosis in patients treated with gamma interferon. Lancet 1: 893-895, 1987.

19. Sykes M: Mixed chimerism and transplant tolerance. Immunity 14: 417-424, 2001.

20. Wood KJ: Passenger leukocytes and microchimerism: What role in tolerance induction? Transplantation 75 (Suppl 9): 17S-20S, 2003.

21. Monaco AP: Chimerism in organ transplantation: conflicting experiments and clinical observations. Transplantation 75 (Suppl 9): 13S-16S, 2003.

22. Elbe A, Foster CA and Stingl G: T-cell receptor alpha beta and gamma delta $\mathrm{T}$ cells in rat and human skin - are they equivalent? Semin Immunol 8: 341-349, 1996.
23. Gardner RV, Velez MC, Ode DL, Lee JW and Correa H: Gamma/delta T-cell lymphoma as a recurrent complication after transplantation. Leuk Lymphoma 45: 2355-2359, 2004.

24. Bergstresser PR, Tigelaar RE, Dees JH and Streilein JW: Thy-1 antigen-bearing dendritic cells populate murine epidermis. J Invest Dermatol 81: 286-288, 1983.

25. Jameson $\mathbf{J}$ and Havran WL: Skin gammadelta T-cell functions in homeostasis and wound healing. Immunol Rev 215: 114-122, 2007.

26. de Jong A, Peña-Cruz V, Cheng TY, Clark RA, Van Rhijn I and Moody DB: CDla-autoreactive T cells are a normal component of the human $\alpha \beta$ T cell repertoire. Nat Immunol 11: 1102-1109, 2010.

27. Lindlahr H: Nature Cure: Philosophy and practice based on the unity of disease and cure. 20th edition. Nature Cure Publishing Company, Chicago, IL, 1922.

28. Ward PA: Acute and chronic inflammation. In: Fundamentals of Inflammation. Serhan CN, Ward PA and Gilroy DW (eds). Cambridge University Press, Cambridge, pp1-16, 2010.

29. Neagu M, Constantin C, Dumitrascu GR, Lupu AR, Caruntu C, Boda D and Zurac S: Inflammation markers in cutaneous melanoma - edgy biomarkers for prognosis. Discoveries 3: e38, 2015.

30. DeNardo DG and Coussens LM: Inflammation and breast cancer. Balancing immune response: Crosstalk between adaptive and innate immune cells during breast cancer progression. Breast Cancer Res 9: 212, 2007.

31. Mantovani A, Allavena P, Sica A and Balkwill F: Cancer-related inflammation. Nature 454: 436-444, 2008.

32. Gonda TA, Tu S and Wang TC: Chronic inflammation, the tumor microenvironment and carcinogenesis. Cell Cycle 8: 2005-2013, 2009.

33. Nedoszytko B, Sokołowska-Wojdyło M, RuckemannDziurdzińska K, Roszkiewicz J and Nowicki RJ: Chemokines and cytokines network in the pathogenesis of the inflammatory skin diseases: Atopic dermatitis, psoriasis and skin mastocytosis Postepy Dermatol Alergol 31: 84-91, 2014.

34. Neagu M, Constantin C and Longo C: Chemokines in the melanoma metastasis biomarkers portrait. J Immunoassay Immunochem 36: 559-566, 2015.

35. Justus CR, Leffler N, Ruiz-Echevarria $M$ and Yang LV: In vitro cell migration and invasion assays. J Vis Exp doi: 10.3791/51046, 2014.

36. Bosanquet DC, Ye L, Harding KG and Jiang WG: Expressed in high metastatic cells (Ehm2) is a positive regulator of keratinocyte adhesion and motility: The implication for wound healing. J Dermatol Sci 71: 115-121, 2013.

37. Oser M, Yamaguchi H, Mader CC, Bravo-Cordero JJ, Arias M, Chen X, Desmarais V, van Rheenen J, Koleske AJ and Condeelis J: Cortactin regulates cofilin and N-WASp activities to control the stages of invadopodium assembly and maturation. J Cell Biol 186: 571-587, 2009.

38. Schäfer M and Werner S: Cancer as an overhealing wound: An old hypothesis revisited. Nat Rev Mol Cell Biol 9: 628-638, 2008.

39. Kong D, Li Y, Wang Z and Sarkar FH: Cancer stem cells and epithelial-to-mesenchymal transition (EMT)-phenotypic cells: Are they cousins or twins? Cancers (Basel) 3: 716-729, 2011.

40. Plikus MV, Guerrero-Juarez CF, Treffeisen E and Gay DL: Epigenetic control of skin and hair regeneration after wounding. Exp Dermatol 24: 167-170, 2015.

41. Yan C, Grimm WA, Garner WL, Qin L, Travis T, Tan N and Han YP: Epithelial to mesenchymal transition in human skin wound healing is induced by tumor necrosis factor-alpha through bone morphogenic protein-2. Am J Pathol 176: 2247-2258, 2010.

42. Leopold PL, Vincent $J$ and Wang $H$ : A comparison of epithelial-to-mesenchymal transition and re-epithelialization. Semin Cancer Biol 22: 471-483, 2012.

43. Graf T and Enver T: Forcing cells to change lineages. Nature 462: 587-594, 2009.

44. Brittan M, Braun KM, Reynolds LE, Conti FJ, Reynolds AR, Poulsom R, Alison MR, Wright NA and Hodivala-Dilke KM: Bone marrow cells engraft within the epidermis and proliferate in vivo with no evidence of cell fusion. J Pathol 205: 1-13, 2005.

45. Sasaki M, Abe R, Fujita Y, Ando S, Inokuma D and Shimizu H: Mesenchymal stem cells are recruited into wounded skin and contribute to wound repair by transdifferentiation into multiple skin cell type. J Immunol 180: 2581-2587, 2008.

46. Egeblad M, Nakasone ES and Werb Z: Tumors as organs: Complex tissues that interface with the entire organism. Dev Cell 18: 884-901, 2010. 
47. Dunham LJ: Cancer in man at site of prior benign lesion of skin or mucous membrane: A review. Cancer Res 32: 1359-1374, 1972.

48. Frei JV and Stephens P: The correlation of promotion of tumour growth and of induction of hyperplasia in epidermal two-stage carcinogenesis. Br J Cancer 22: 83-92, 1968

49. Kemp CJ: Multistep skin cancer in mice as a model to study the evolution of cancer cells. Semin Cancer Biol 15: 460-473, 2005.

50. Verma AK, Wheeler DL, Aziz MH and Manoharan H: Protein kinase Cepsilon and development of squamous cell carcinoma, the nonmelanoma human skin cancer. Mol Carcinog 45: 381-388, 2006.

51. Rundhaug JE and Fischer SM: Tumor promoters and models of promotion. In: Comprehensive toxicology. Vol 12. Sipes IG McQueen CA and Gandolfi AJ (eds). Elsevier Sciences Ltd., New York, NY, pp325-348, 1997.

52. Abel EL, Angel JM, Kiguchi K and DiGiovanni J: Multi-stage chemical carcinogenesis in mouse skin: Fundamentals and applications. Nat Protoc 4: 1350-1362, 2009.

53. DiGiovanni J: Modification of multistage skin carcinogenesis in mice. In: Modification of tumor development in rodents. Vol 33. Ito N and Sugano H (eds). Karger, Basel, pp192-229, 1991.

54. Segrelles C,Lu J,Hammann B, Santos M, Moral M, Cascallana JL, Lara MF, Rho O, Carbajal S, Traag J, et al: Deregulated activity of Akt in epithelial basal cells induces spontaneous tumors and heightened sensitivity to skin carcinogenesis. Cancer Res 67: 10879-10888, 2007.

55. Amornphimoltham P, Leelahavanichkul K, Molinolo A, Patel V and Gutkind JS: Inhibition of Mammalian target of rapamycin by rapamycin causes the regression of carcinogen-induced skin tumor lesions. Clin Cancer Res 14: 8094-8101, 2008.

56. Bassi DE and Klein-Szanto AJP: Current protocols in pharmacology. In: Carcinogen-induced animal models of head and neck squamous cell carcinoma. John Wiley \& Sons, Inc., Hoboken, NJ, pp14.12.11-14.12.19, 2007.

57. Ashman LK, Murray AW, Cook MG and Kotlarski I: Two-stage skin carcinogenesis in sensitive and resistant mouse strains Carcinogenesis 3: 99-102, 1982.

58. Wolf CR and Henderson CJ: Use of transgenic animals in understanding molecular mechanisms of toxicity. J Pharm Pharmacol 50: 567-574, 1998.

59. Sundberg JP, Sundberg BA and Beamer WG: Comparison of chemical carcinogen skin tumor induction efficacy in inbred, mutant, and hybrid strains of mice: Morphologic variations of induced tumors and absence of a papillomavirus cocarcinogen. Mol Carcinog 20: 19-32, 1997.

60. McCormick DL and Moon RC: Antipromotional activity of dietary $\mathrm{N}$-(4-hydroxyphenyl)retinamide in two-stage skin tumorigenesis in CD-1 and SENCAR mice. Cancer Lett 31: 133-138, 1986.

61. Warren BS, Slaga TJ. Mechanisms of inhibition of tumor progression. Basic Life Sci 61: 279-289, 1993.

62. Xu H, Cheepala S, McCauley E, Coombes K, Xiao L, Fischer SM and Clifford JL: Chemoprevention of skin carcinogenesis by phenylretinamides: retinoid receptor-independent tumor suppression. Clin Cancer Res 12 (3 Pt 1): 969-979, 2006

63. Miller SJ, Wei ZG, Wilson C, Dzubow L, Sun TT and Lavker RM: Mouse skin is particularly susceptible to tumor initiation during early anagen of the hair cycle: Possible involvement of hair follicle stem cells. J Invest Dermatol 101: 591-594, 1993.

64. Marinescu B, Isvoranu G, Constantin C, Coman C, Zurac S, Căruntu C, Boda D, Neagu M and Călin M: Experimental model of chemically induced skin carcinogenesis in mice. Rev Rom Med Vet 20: 97-104, 2010.

65. Home Office: Animals (Scientific Procedures) Act 1986: Code of Practice for the Housing and Care of Animals Used in Scientific Procedures. https://www.gov.uk/government/uploads/ system/uploads/attachment_data/file/228831/0107.pdf. Accessed January 20, 2016.

66. Diaconeasa A, Boda D, Neagu M, Constantin C, Căruntu C, Vlădău L and Guţu D: The role of confocal microscopy in the dermato-oncology practice. J Med Life 4: 63-74, 2011.

67. Căruntu C and Boda D: Evaluation through in vivo reflectance confocal microscopy of the cutaneous neurogenic inflammatory reaction induced by capsaicin in human subjects. J Biomed Opt 17: 085003, 2012

68. Li Y, Gonzalez S, Terwey TH, Wolchok J, Li Y, Aranda I, Toledo-Crow R and Halpern AC: Dual mode reflectance and fluorescence confocal laser scanning microscopy for in vivo imaging melanoma progression in murine skin. J Invest Dermatol 125: 798-804, 2005
69. Li Z, Huang P, Zhang X, Lin J, Yang S, Liu B, Gao F, Xi P, Ren Q and Cui D: RGD-conjugated dendrimer-modified gold nanorods for in vivo tumor targeting and photothermal therapy. Mol Pharm 7: 94-104, 2010.

70. Căruntu C, Boda D, Guţu DE and Căruntu A: In vivo reflectance confocal microscopy of basal cell carcinoma with cystic degeneration. Rom J Morphol Embryol 55: 1437-1441, 2014.

71. Căruntu C, Boda D, Căruntu A, Rotaru M, Baderca F and Zurac S: In vivo imaging techniques for psoriatic lesions. Rom J Morphol Embryol 55 (Suppl 3): 1191-1196, 2014.

72. Croix CS, Zipfel WR and Watkins SC: Potential solutions for confocal imaging of living animals. Biotechniques 43 (Suppl 1): 14-19, 2007.

73. Fujiki H, Sueoka E and Suganuma M: Tumor promoters: From chemicals to inflammatory proteins. J Cancer Res Clin Oncol 139: 1603-1614, 2013.

74. Neagu M, Constantin C, Martin D, Albulescu L, Iacob N and Ighigeanu D: Whole body microwave irradiation for improved dacarbazine therapeutical action in cutaneous melanoma mouse model. Radiol Res Pract 2013: 414816, 2013.

75. Schwarz M, Münzel PA and Braeuning A: Non-melanoma skin cancer in mouse and man. Arch Toxicol 87: 783-798, 2013.

76. Prasad R and Katiyar SK: Ultraviolet radiation-induced inflammation activates $\beta$-catenin signaling in mouse skin and skin tumors. Int J Oncol 44: 1199-1206, 2014.

77. Huang YF, Yeh HY and Soo VW: Inferring drug-disease associations from integration of chemical, genomic and phenotype data using network propagation. BMC Med Genomics 6 (Suppl 3): S4, 2013.

78. Yang AY, Lee JH, Shu L, Zhang C, Su ZY, Lu Y, Huang MT, Ramirez C, Pung D, Huang Y, et al: Genome-wide analysis of DNA methylation in UVB- and DMBA/TPA-induced mouse skin cancer models. Life Sci 113: 45-54, 2014.

79. Uekusa S, Kawashima H, Sugito K, Yoshizawa S, Shinojima Y, Igarashi J, Ghosh S, Wang X, Fujiwara K, Ikeda T, et al: Nr4a3, a possibile oncogenic factor for neuroblastoma associated with CpGi methylation within the third exon. Int J Oncol 44: 1669-1677, 2014.

80. Saito M, Okumura K, Miura I, Wakana S, Kominami R and Wakabayashi Y: Identification of Stmm3 locus conferring resistance to late-stage chemically induced skin papillomas on mouse chromosome 4 by congenic mapping and allele-specific alteration analysis. Exp Anim 63: 339-348, 2014.

81. Okumura K, Saito M, Isogai E, Miura I, Wakana S, Kominami R and Wakabayashi Y: Congenic mapping and allele-specific alteration analysis of Stmm1 locus conferring resistance to early-stage chemically induced skin papillomas. PLoS One 9: e97201, 2014

82. Han G, Lu SL, Li AG, He W, Corless CL, Kulesz-Martin M and Wang XJ: Distinct mechanisms of TGF-beta1-mediated epithelial-to-mesenchymal transition and metastasis during skin carcinogenesis. J Clin Invest 115: 1714-1723, 2005.

83. Matsumoto T, Jiang J, Kiguchi K, Ruffino L, Carbajal S, Beltrán L, Bol DK, Rosenberg MP and DiGiovanni J: Targeted expression of c-Src in epidermal basal cells leads to enhanced skin tumor promotion, malignant progression, and metastasis. Cancer Res 63: 4819-4828, 2003.

84. Chen J and Roop DR: Genetically engineered mouse models for skin research: Taking the next step. J Dermatol Sci 52: 1-12, 2008.

85. Wilker E, Lu J, Rho O, Carbajal S, Beltrán L and DiGiovanni J: Role of PI3K/Akt signaling in insulin-like growth factor-1 (IGF-1) skin tumor promotion. Mol Carcinog 44: 137-145, 2005.

86. Hayes J, Peruzzi PP and Lawler S: MicroRNAs in cancer: biomarkers, functions and therapy. Trends Mol Med 20: 460-469, 2014.

87. Acunzo M, Romano G, Wernicke D and Croce CM: MicroRNA and cancer - a brief overview. Adv Biol Regul 57: 1-9, 2015.

88. Syed DN, Khan MI, Shabbir M and Mukhtar H: MicroRNAs in skin response to UV radiation. Curr Drug Targets 14: 1128-1134, 2013.

89. Singh A, Willems E, Singh A, Hafeez BB, Ong IM, Mehta SL and Verma AK: Ultraviolet radiation-induced tumor necrosis factor alpha, which is linked to the development of cutaneous SCC, modulates differential epidermal microRNAs expression. Oncotarget: Feb 22, 2016 (Epub ahead of print).

90. Skourti E, Logotheti S, Kontos CK, Pavlopoulou A, Dimoragka PT, Trougakos IP, Gorgoulis V, Scorilas A, Michalopoulos I and Zoumpourlis V: Progression of mouse skin carcinogenesis is associated with the orchestrated deregulation of miR-200 family members, miR-205 and their common targets. Mol Carcinog: Aug 27, 2015 (Epub ahead of print). 
91. Chen T: The role of MicroRNA in chemical carcinogenesis. J Environ Sci Health C Environ Carcinog Ecotoxicol Rev 28: 89-124, 2010

92. Corsini LR, Bronte G, Terrasi M, Amodeo V, Fanale D, Fiorentino E, Cicero G, Bazan V and Russo A: The role of microRNAs in cancer: diagnostic and prognostic biomarkers and targets of therapies. Expert Opin Ther Targets 16 (Suppl 2): S103-S109, 2012.

93. Pogribny IP, Beland FA, Rusyn I: The role of microRNAs in the development and progression of chemical-associated cancers. Toxicol Appl Pharmacol: Nov 24, 2015 (Epub ahead of print).

94. Shen J, Abel EL, Riggs PK, Repass J, Hensley SC, Schroeder LJ, Temple A, Chau A, McClellan SA, Rho O, et al: Proteomic and pathway analyses reveal a network of inflammatory genes associated with differences in skin tumor promotion susceptibility in DBA/2 and C57BL/6 mice. Carcinogenesis 33: 2208-2219, 2012.

95.Hemler ME: Tetraspanin functions and associated microdomains. Nat Rev Mol Cell Biol 6: 801-811, 2005.

96.Li Q, Yang XH, Xu F, Sharma C, Wang HX, Knoblich K, Rabinovitz I, Granter SR and Hemler ME: Tetraspanin CD151 plays a key role in skin squamous cell carcinoma. Oncogene 32: 1772-1783, 2013.

97.Hara T, Matsumura S, Hakuno F, Takahashi S and Chida K PKC $\alpha$ suppresses 7,12-dimethylbenz[a]anthracene-induced skin tumor formation. Anticancer Res 32: 3097-3101, 2012.

98. Suganuma M, Okabe S, Kurusu M, Iida N, Ohshima S, Saeki Y, Kishimoto T and Fujiki H: Discrete roles of cytokines, TNF- $\alpha$, IL-1, IL-6 in tumor promotion and cell transformation. Int J Oncol 20: 131-136, 2002

99. Matei C, Tampa M, Ion RM, Georgescu SR, Dumitrascu GR, Constantin $C$ and Neagu M: Protein microarray for complex apoptosis monitoring of dysplastic oral keratinocytes in experimental photodynamic therapy. Biol Res 47: 33, 2014.

100. Tanase CP, Albulescu R and Neagu M: Application of 3D hydrogel microarrays in molecular diagnostics: Advantages and limitations. Expert Rev Mol Diagn 11: 461-464, 2011

101.Kangsamaksin T, Park HJ, Trempus CS and Morris RJ: A perspective on murine keratinocyte stem cells as targets of chemically induced skin cancer. Mol Carcinog 46: 579-584, 2007.

102. Trempus CS, Morris RJ, Ehinger M, Elmore A, Bortner CD, Ito M, Cotsarelis G, Nijhof JG, Peckham J, Flagler N, et al: CD34 expression by hair follicle stem cells is required for skin tumor development in mice. Cancer Res 67: 4173-4181, 2007.

103. Klein EA: Can prostate cancer be prevented? Nat Clin Pract Urol 2: 24-31, 2005.

104. Sagawa Y, Futakuchi M, Xu J,Fukamachi K, Sakai Y, Ikarashi Y, Nishimura T, Suzui M, Tsuda H and Morita A: Lack of promoting effect of titanium dioxide particles on chemically-induced skin carcinogenesis in rats and mice. J Toxicol Sci 37: 317-327, 2012.

105. Bhatia A, Singh B, Raza K, Shukla A, Amarji B and Katare OP: Tamoxifen-loaded novel liposomal formulations: Evaluation of anticancer activity on DMBA-TPA induced mouse skin carcinogenesis. J Drug Target 20: 544-550, 2012.

106. Enoki T, Tominaga T, Takashima F, Ohnogi H, Sagawa H and Kato I: Anti-tumor-promoting activities of agaro-oligosaccharides on two-stage mouse skin carcinogenesis. Biol Pharm Bull 35: 1145-1149, 2012

107. Kowalczyk MC, Spears E, Narog M, Zoltaszek R, Kowalczyk P, Hanausek M, Yoshimi N, Slaga TJ and Walaszek Z: Modulation of biomarkers related to tumor initiation and promotion in mouse skin by a natural $\beta$-glucuronidase inhibitor and its precursors. Oncol Rep 26: 551-556, 2011.

108. Meghea A, Murariu A, Tanase C and Codorean E: Heavy metals contamination of commercial fish foodstuff - potential health risks on human consumers. Environ Eng Manag J 8: 233-236, 2009.

109. Kundu JK, Shin YK and Surh YJ: Resveratrol modulates phorbol ester-induced pro-inflammatory signal transduction pathways in mouse skin in vivo: NF-kappaB and AP-1 as prime targets. Biochem Pharmacol 72: 1506-1515, 2006.

110. Kleiner HE, Vulimiri SV, Starost MF, Reed MJ and DiGiovanni J: Oral administration of the citrus coumarin, isopimpinellin, blocks DNA adduct formation and skin tumor initiation by 7,12-dimethylbenz[a]anthracene in SENCAR mice. Carcinogenesis 23: 1667-1675, 2002.
111. Singh RP, Tyagi AK, Zhao J and Agarwal R: Silymarin inhibits growth and causes regression of established skin tumors in SENCAR mice via modulation of mitogen-activated protein kinases and induction of apoptosis. Carcinogenesis 23: 499-510, 2002.

112. Dao V, Pandeswara S, Liu Y, Hurez V, Dodds S, Callaway D, Liu A, Hasty P, Sharp ZD and Curiel TJ: Prevention of carcinogen and inflammation-induced dermal cancer by oral rapamycin includes reducing genetic damage. Cancer Prev Res (Phila) 8: 400-409, 2015

113. Pinheiro KS, Ribeiro DR, Alves AV, Pereira-Filho RN Oliveira CR, Lima SO, Reis FP, Cardoso JC and Albuquerque-Júnior RL: Modulatory activity of Brazilian red propolis on chemically induced dermal carcinogenesis. Acta Cir Bras 29: 111-117, 2014

114. Manoharan S and Selvan MV: Chemopreventive potential of geraniol in 7,12-dimethylbenz(a) anthracene (DMBA) induced skin carcinogenesis in Swiss albino mice. J Environ Biol 33: 255-260, 2012

115. Sharmila R and Manoharan S: Anti-tumor activity of rosmarinic acid in 7,12-dimethylbenz(a)anthracene (DMBA) induced skin carcinogenesis in Swiss albino mice. Indian J Exp Biol 50: 187-194, 2012.

116. Man'cheva TA, Demidov DV, Plotnikova NA, Kharitonova TV, Pashkevich IV and Anisimov VN: Melatonin and metformin inhibit skin carcinogenesis and lipid peroxidation induced by benz(a)pyrene in female mice. Bull Exp Biol Med 151: 363-365, 2011

117. Hu G, Zhang L, Rong Y, Ni X and Sun Y: Downstream carcinogenesis signaling pathways by green tea polyphenols: A translational perspective of chemoprevention and treatment for cancers. Curr Drug Metab 15: 14-22, 2014.

118. Birt DF, Pinch HJ, Barnett T, Phan A and Dimitroff K: Inhibition of skin tumor promotion by restriction of fat and carbohydrate calories in SENCAR mice. Cancer Res 53: 27-31, 1993.

119. Moore T, Beltran L, Carbajal S, Strom S, Traag J, Hursting SD and DiGiovanni J: Dietary energy balance modulates signaling through the Akt/mammalian target of rapamycin pathways in multiple epithelial tissues. Cancer Prev Res (Phila) 1: 65-76, 2008.

120. Stewart JW, Koehler K, Jackson W, Hawley J, Wang W, Au A, Myers R and Birt DF: Prevention of mouse skin tumor promotion by dietary energy restriction requires an intact adrenal gland and glucocorticoid supplementation restores inhibition. Carcinogenesis 26: 1077-1084, 2005.

121. Katiyar SK: Silymarin and skin cancer prevention: Anti-inflammatory, antioxidant and immunomodulatory effects (Review). Int J Oncol 26: 169-176, 2005.

122. Vaid M and Katiyar SK: Molecular mechanisms of inhibition of photocarcinogenesis by silymarin, a phytochemical from milk thistle (Silybum marianum L. Gaertn.) (Review). Int J Oncol 36: 1053-1060, 2010.

123. Deep G and Agarwal R: Chemopreventive efficacy of silymarin in skin and prostate cancer. Integr Cancer Ther 6: 130-145, 2007.

124. Benjamin CL and Ananthaswamy HN: p53 and the pathogenesis of skin cancer. Toxicol Appl Pharmacol 224: 241-248, 2007.

125. Kiaris H and Spandidos DA: Mutations of ras genes in human tumors (review). Int J Oncol 7: 413-421, 1995.

126. Hennings H, Spangler EF, Shores R, Mitchell P, Devor D, Shamsuddin AK, Elgjo KM and Yuspa SH: Malignant conversion and metastasis of mouse skin tumors: A comparison of SENCAR and CD-1 mice. Environ Health Perspect 68: 69-74, 1986.

127.Liu J, Mansouri K, Judson RS, Martin MT, Hong H, Chen M, $\mathrm{Xu} \mathrm{X}$, Thomas RS and Shah I: Predicting hepatotoxicity using ToxCast in vitro bioactivity and chemical structure. Chem Res Toxicol 28: 738-751, 2015.

128. Bulman A, Neagu M and Constantin C: Immunomics in Skin Cancer - Improvement in Diagnosis, Prognosis and Therapy Monitoring. Curr Proteomics 10: 202-217, 2013.

129. Spandidos DA: A unified theory for the development of cancer. Biosci Rep 6: 691-708, 1986. 